\title{
Effects of Neonatal Undernutrition on Development of the Dorsolateral Prefrontal Cortex Pyramidal Cells in the Rat
}

\author{
Carmen Torrero, Mirelta Regalado, Lorena Rubio, Manuel Salas \\ Department of Developmental Neurobiology and Neurophysiology, Institute of Neurobiology, National Autonomous \\ University of Mexico, Campus UNAM Juriquilla, Queretaro, Mexico \\ Email: masal@unam.mx
}

Received November 24, 2013; revised December 29, 2013; accepted January 15, 2014

Copyright (c) 2014 Carmen Torrero et al. This is an open access article distributed under the Creative Commons Attribution License, which permits unrestricted use, distribution, and reproduction in any medium, provided the original work is properly cited. In accordance of the Creative Commons Attribution License all Copyrights (c) 2014 are reserved for SCIRP and the owner of the intellectual property Carmen Torrero et al. All Copyright (C) 2014 are guarded by law and by SCIRP as a guardian.

\section{ABSTRACT}

The dorsolateral prefrontal cortex (dIPFC) of the rat plays a role in the encoding of neuronal signals involved in conflict-induced behavioral adjustment, working memory, planning and executive abilities, attentional control and other cognitive responses. In altricial species, early perinatal undernutrition interferes with the morphofunctional organization of a number of central nervous system (CNS) structures including the prefrontal cortex. The effects of neonatal undernutrition on dendritic arbor density, perikaryon measurements, and the number of spines (detected by rapid-Golgi) of basilar dendritic segments in layer III pyramidal neurons of the dIPFC were examined in male Wistar rats on postnatal (PDs) 12, 20, and 30. In the underfed (U) subjects the distal portions of the dendritic arbors had a consistent hipoplasia, mainly on PD 30, with reduced cross sectional area, perimeter, and spine densities on the basilar dendrites on all days studied. Thus, the alterations of the dIPFC pyramidal neurons may interfere with the plastic synaptic activity and cognitive performance of rats subjected to the stress of early underfeeding. Characterizing these anatomical alterations may help to understand the disrupted cognitive processes associated with neonatal undernutrition.

\section{KEYWORDS}

\section{Neonatal Undernutrition; Prefrontal Cortex Development; Stressed Rats}

\section{Introduction}

In rodents, perinatal food restriction interferes with the neocortical morphofunctional and subcortical synaptic organization of the brain and has short- and long-term behavioral, biochemical, and electrophysiological consequences that limit the expression of brain cognitive capabilities such as attentional processes, emotional and, maternal behavior, working memory, goal-directed behavior, and visuospatial learning among others [1-10]. In this regard, alterations in the number and density of neocortical dendritic arbor, the reduced number of spines, and maldistribution of neurons may promote deficits in the neocortical connectivity, neuronal interactions, and the integration of complex physiological processes that may correlate with human brain disorders or abnormal adaptive behavior in animal models [11-15].

Studies in rodents have revealed that undernutrition during gestation or lactation results in permanent central nervous system (CNS) alterations, in regions including the motor, primary sensory, and cortical association areas of the cortex, particularly in the dorsolateral prefrontal cortex (dlPFC) [12,16-18]. In most of the studies, food restriction was established during the pre- and neonatal periods, and in few of them only during the lactating period, and the subjects performed poorly with respect to various types of responses, depending on the nutritional manipulations, neuronal parameters measured, and difficulty of the behavioral task employed. However, it is not clear how to distinguish nutritional effects from environmental influences, or the interactions between them. During the lactating period, the mother-litter bonds are essential for the development of the offspring pup's physical, behavioral, cognitive, and endocrine responses to stress [19-21]. In this context, exposure of the lactating 
dam to stressful conditions such as pup and nesting manipulations, food deprivation, etc., can interfere with maternal care [4,22-25]. Additionally, separation from the mother or increases in the quality or quantity of handling given to the pups may improve their anatomical, electrophysiological, and long-term adaptive behavioral performance [19,26-29]. In the current study we provoke neonatal undernutrition by using the paradigm of transferring half of the litter (4 out of 8 pups) daily for $12 \mathrm{~h}$ from the nest to a humid incubator to maintain the pup's body temperature (0800 - $2000 \mathrm{~h})$, and then returning them to the nest with their own lactating dam from postnatal days (PDs) 1-23 [22,30]. Using this procedure we compared an undernourished group with food and sensory deprivation in an incubator, with a group fed normally in the nest by a lactating dam that provides complete maternal care.

The aim of this study was to test whether neonatal undernutrition and sensory deprivation are associated with a dendritic arbor hypoplasia in layer III dlPFC pyramidal neurons. Because the dendritic spines are where axonal afferents converge and encoded ascending neuronal messages are integrated in pyramidal neurons, we evaluate the dendritic density and the number of spines on the basilar dendrites of layer 3 pyramidal neurons, parameters that may correlate with the long-term cognitive deficits commonly seen in early underfed rats.

\section{Material and Methods}

\subsection{Animals}

Thirty-six male Wistar rats (Rattus norvegicus), descendants of a stock originally obtained from Harlan Sprague-Dawley, Inc., were used as subjects. Animal care and protocols were approved by the National Autonomous University of Mexico according to Local Animal Committees and were in compliance with the guidelines for the care and use of mammals in Neurocience and Behavioral Research [31]. Subjects were obtained from 8 pregnant, nulliparous dams, 100 - 120 days of age (200 $250 \mathrm{~g})$. All animals were maintained in an automatically controlled room at $22^{\circ} \mathrm{C} \pm 2{ }^{\circ} \mathrm{C}, 50 \%$ humidity on a 12-h/12-h light/dark cycle (lights on at 07:00 h), with water and food (Purina chow) ad libitum. For mating, groups of four virgin female rats were house with a male of similar age. Sperm-positive females were placed one weak before delivery in individual plastic maternity cages $\left(35 \times 27 \times 17 \mathrm{~cm}^{3}\right)$ with grill tops, and wood shavings as nesting material. Births were checked for daily at 08:00 and 18:00 h. Pups found at that time were considered to be 0 days of age. The day after birth, pups were weighed and sexed, and the litter was adjusted to 8 pups per mother (four males and four females). The redistribution was intended to minimize genetic and nutritional differences that may influence the experimental results. The presence of the bilateral thoracic and abdominal line of nipples and the shorter anogenital distance in the females were used as criteria for sex recognition [32].

\subsection{Nutritional Procedures}

\subsubsection{The Undernourished Group (UG)}

The undernourished group (UG) of male subjects $(\mathrm{n}=15)$ came from at least four different litters. Neonatal undernutrition was produced by transferring the same $(n=4)$ half of the litter from the nest to an incubator maintained at $29^{\circ} \mathrm{C}$, for a $12-\mathrm{h}$ span (08:00-20:00 h), daily from PD 1 to $\mathrm{PD} 24$. In all cases, underfed pups of one litter were placed together with the underfed pups from at least two other litters inside the incubator to ensure some physical interaction among underfed pups during the 12-h period of separation from the dam, although with a significant reduction compared to the environmental and sensory signals of the nest. During the home encounter with the mother and the 12-h period of mother-litter interactions, pups receive and provide direct sensorimotor cutaneous stimulation from littermates and from the dam's fur, maternal body licking, whisking movements, motor activity, and suckling that may ameliorate the effects of maternal separation [33-35]. This paradigm was chosen because most of the dlPFC neurogenesis occurred prenatally, following different cytogenetic gradients, during the prenatal period [36]. All the UG subjects used here were undernourished during the light phase of the cycle with no food and water available. The pups were returned to their home cage with the mother and control littermates for $12-\mathrm{h}$ to receive maternal care, and be exposed to the nest environmental cues and regular animal room routine. Rats were weaned on PD 25 and housed in plastic cages $\left(60 \times 32 \times 20 \mathrm{~cm}^{3}\right)$ in groups of 4 subjects of the same treatment per cage. This paradigm of undernourishment introduced not only the effects of daily food restriction but also the effects of maternal sensory deprivation of newborns compared with other underfeeding procedures [37]. Mortality between birth and PD 30 was 4\% - 5\% in the ad libitum group and $10 \%$ in the undernourished group.

\subsubsection{The Control Group (CG)}

The control group (CG) of male subjects $(n=15)$ came from four different, well-fed litters that had been adjusted at birth to 8 pups per mother (four males and four females), and were maintained continuously with the mother in the nest environment except for a daily 3-min period (PDs 1 to 24) when they were gently removed from the nest and introduced into the incubator. Control subjects were then returned to the nest with the mother for the following 24-h. After weaning on day 25, subjects of both dietary conditions had free access to water and solid 
food. To evaluate the effects of the two nutritional treatments (CG $=5$ rats; UG $=5$ rats) on physical growth, the pup's body and brain weights and ages were noted. The older group of animals (PD 30) had a 6-day period of dietary rehabilitation prior to sacrifice.

\subsection{Histology}

A total of 30 male rats were subjected to two dietary treatments ( $n=15$, CG, and $n=15$, UG), each with three groups. They were weighed, deeply anesthetized with ether, and decapitated at PDs 12, 20, and 30, resulting in five subjects per age and treatment. The brain, including the olfactory bulbs and the brain stem sections at the first cervical segment was removed and weighed wet, sectioned into three coronal blocks ( $3 \mathrm{~mm}$ each), and placed for 2 - 3 days in buffered $10 \%$ formaldehyde. Tissues were transferred for $72 \mathrm{~h}$ into a solution containing 2.4 $\mathrm{ml}$ potassium dichromate and $0.2 \%$ osmium tetroxide in distilled water. The sections were stained by a variant of the rapid Golgi technique [38], and they were transferred for $24 \mathrm{~h}$ into a solution of $0.75 \%$ silver nitrate in distilled water. Sections (150 - $200 \mu \mathrm{m}$ thick) of the dlPFC obtained with a sliding microtome were put into absolute alcohol for 15-min, then transferred to terpineol (15 min), then to xylol (15 $\mathrm{min})$ and mounted serially. The slides were coded to ensure blind evaluation with respect to age and dietary treatment of subjects. Moreover, during the neuronal image digitizing, the experimenter had access only to the code numbers and not to the ages and experimental conditions of the brain material. Identification and location of the dIPFC area were based on the Paxinos and Watson atlas [39]. Anterior posterior coordinates for the localization of the dlPFC corresponded to values ranging from Bregma 2.70 to $1.70 \mathrm{~mm}$.

\subsection{Neuronal Measurements}

The present study was based on a total of 210 well-impregnated, layer III dIPFC pyramidal neurons whose basilar dendritic field was confined to one section, as evidenced by light microscopy for each experimental condition, age group, and neuronal parameter (Figure 1). Basilar dendritic arbor measurements were obtained by counting the number of $1^{\text {st }}, 2^{\text {nd }}, 3^{\text {rd }}, 4^{\text {th }}, 5^{\text {th }}, 6^{\text {th }}$ and $7^{\text {th }}$ dendritic orders. Basilar dendritic branches leaving the cell body were defined as first order, while those which branched from the former were considered second order, and so on. The dendritic density was measured by placing the cell body and primary dendrites at the center of the first of a series of six concentric rings (spaced at $40-\mu \mathrm{m}$ intervals) and counting all dendritic crossings with larger individual rings [40]. In all cases neuronal measurements were made at a magnification of $400 \mathrm{X}$ using an image-digitazing system (Perception Analysis

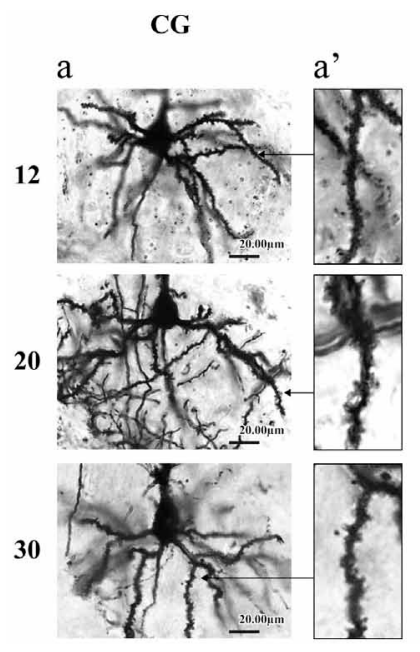

(A)

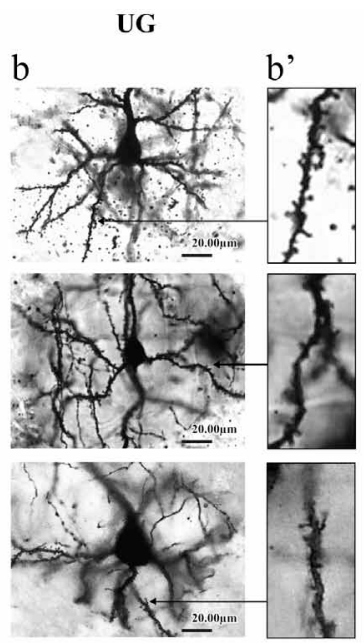

(B)

Figure 1. (A) Rapid Golgi representative photomicrographs of pyramidal neurons showing coronal sections through the dIPFC from CG (a), and UG (b), animals at PDs 12, 20, and 30; (B) Rapid Golgi-impregnated dendritic spine segments $(50 \mu \mathrm{m})$ from basilar dendrites of pyramidal cells from the CG (a'), and UG (b') rats during development. Note, the reduced dendritic arborizations and dendritic spines in the UG compared to the CG rats. Arrows in a' and b' indicate places where dendritic segments were taken.

System by Human-Computer Interface, Cambridge, UK).

To reduce the likelihood of a biased selection of pyramidal cells, the slides were first scanned at low magnification 25X for completely stained basilar dendrites that gradually tapered to an end without abrupt termination. After pyramidal cells designated for spine counting had been identified, spines were quantified at a magnification of $675 \mathrm{X}$. The number of spines free of chrome-silver precipitates, blood vessels, etc., were counted and recorded for each of the basilar dendritic segments. Four segments (50 $\mu \mathrm{m}$ long each) per neuron were distributed as follows: basilar (2) dendritic branches at each side of the neuron. Spines were counted in a minimum of 5 , layer III cortical pyramidal neurons from each animal of the two dietary treatments and three ages (a total of 102 neurons).

\subsection{Statistics}

The following ANOVA comparisons were used to analyze the score differences among ages and dietary conditions: 1) scores for body and wet brain weight were compared using a two-way ANOVA, 2 (dietary treatments) X 3 (ages); 2) the effects of undernutrition on the dendritic order and dendritic density of branches during development were analyzed by using a three-way ANOVA, 2 (dietary treatments) X 3 (ages) X 7 (dendritic orders) or 6 (concentric rings). 3) Measurements of the number of spines for individual animals were pooled to 
obtain a mean and standard error for each age and treatment, and were compared in a two-way ANOVA 3 (ages) $\mathrm{X} 2$ (dietary treatments). To detect cumulative effects of undernutrition on the two dendritic measurements, the effects of the diet on all dendritic arbors at various ages and the total number of dendritic orders or dendritic crossings, a two-way ANOVA was used, 2 (dietary treatments) X 3 (ages). The post hoc statistical comparisons between experimental groups were made by using the Fisher LSD post hoc test. The level of significance was set at $\mathrm{p} \leq 0.05$ for all analyses.

\section{Results}

\subsection{Body and Brain Weight Effects}

The ANOVA comparisons between the experimental groups indicated significant body weight reductions in the UG subjects compared to the CG animals, $\mathrm{F}(1,24)=$ 372.13, $\mathrm{p}<0.0001$, and body weight was also affected by age, $F(2,24)=1613.17, \mathrm{p}<0.0001$; there was a significant interaction diet by age, $\mathrm{F}(2,24)=16.14$, $\mathrm{p}<$ 0.0001 . Post hoc comparisons indicated significant body weight reductions $(\mathrm{p}<0.05)$ in the UG rats at all ages tested (Table 1). Furthermore, brain weight comparisons showed lower values for the UG compared to those of the CG animals, $\mathrm{F}(1,24)=12.77, \mathrm{p}<0.0015$; brain weight was also modified by age, $\mathrm{F}(2,24)=61.61$, $\mathrm{p}<$ 0.0001 , without a significant interaction between the diet by the age. Post hoc comparisons showed significantly lower brain weight $(\mathrm{p}<0.05)$ for the UG subjects at PDs 20 , and 30 than in the corresponding controls (Table 1 ).

\subsection{Dendritic Arbor Effects}

The number of dendritic branches of the pyramidal neurons was modified by the diet, $F(1,102)=46.58$, $\mathrm{p}<$ 0.0001 , and age, $\mathrm{F}(2,102)=6.12, \mathrm{p}<0.0001$, and there was a significant interaction diet by age, $F(2,102)=6.19$, $\mathrm{p}<0.002$. There were significant differences between the different orders (7) of dendritic complexity, $F(6,612)=$ 538.23, $\mathrm{p}<0.0001$, with significant interactions order by diet, $F(6,612)=24.34, p<0.0001$, and dendritic order by age, $F(12,612)=5.04, p<0.0001$. There were total effects associated with diet, $\mathrm{F}(1,102)=21.07, \mathrm{p}<0.00001$ and with age, $\mathrm{F}(2,102)=15.40, \mathrm{p}<0.02$, and a significant interaction between them, $(2,102)=4.21$, $\mathrm{p}<0.01$. Post hoc comparisons indicated significant score reductions ( $\mathrm{p}<0.05$ ) in the UG dendritic orders 3 and 4 at PDs 12 , and 20, and in the orders 2, 3, 4, 5, at PD 30. There was also a cumulative effect of orders at all ages tested ( $p$ $<0.05$ ) (Figure 2(a)).

The density of the dendritic arbor of pyramidal cells, taken as the number of crossings of dendrites per circle, showed significant reductions in the UG animals, $\mathrm{F}(1,102)=21.07, \mathrm{p}<0.0001$ compared to the CG, there
Table 1. Mean values \pm SEM of body and brain weights (g) in $C G$ and $U G$ rats during development.

\begin{tabular}{cccccc}
\hline $\begin{array}{c}\text { Age } \\
\text { (days) }\end{array}$ & \multicolumn{2}{c}{ Body weight } & \multicolumn{3}{c}{ Brain weight } \\
\hline & CG & UG & CG & UG \\
12 & $26.72 \pm 0.54$ & $19.00 \pm 0.15^{*}$ & $1.22 \pm 0.02$ & $1.14 \pm 0.01$ \\
20 & $44.60 \pm 1.20$ & $28.46 \pm 0.38^{*}$ & $1.40 \pm 0.01$ & $1.30 \pm 0.01^{*}$ \\
30 & $77.18 \pm 1.35$ & $61.36 \pm 0.67^{*}$ & $1.58 \pm 0.05$ & $1.48 \pm 0.03^{*}$ \\
Total & $49.50 \pm 5.61$ & $36.27 \pm 4.85^{*}$ & $1.40 \pm 0.04$ & $1.30 \pm 0.03^{*}$ \\
Factors & df & F & p $<$ & F & p $<$ \\
Nutr (A) & 1,24 & 372.13 & 0.0001 & 12.77 & 0.0015 \\
Age (B) & 2,24 & 1613.17 & 0.0001 & 61.61 & 0.0001 \\
A * B & 2,24 & 16.14 & 0.0001 & 0.06 & NS \\
\hline
\end{tabular}

${ }^{*} \mathrm{P}<0.05 \%$, NS $=$ Not significant. Total indicates the average values for all ages.

was a significant effect of age, $\mathrm{F}(2,102)=15.40, \mathrm{p}<$ 0.0001 , and a significant interaction diet by age, $F(2,102)$ $=4.21, \mathrm{p}<0.01$. When the statistical comparison was done based on the dendritic density, significant differences were obtained, $F(5,510)=285.76, p<0.0001$. The significant interactions between the circle length and diet, $\mathrm{F}(5,510)=5.43, \mathrm{p}<0.0001$, circle by age, $\mathrm{F}(10,510)=$ 2.39, $\mathrm{p}<0.008$, and circle by diet, $\mathrm{F}(10,510)=2.14$, $\mathrm{p}<$ 0.01 . There was a total effect associated with the age, $\mathrm{F}(2,102)=6.12, \mathrm{p}<0.003$, and a significant interaction diet by age, $\mathrm{F}(2,102)=6.19$, $\mathrm{p}<0.002$. Post hoc comparisons showed significant score reductions $(\mathrm{p}<0.05)$ in the dendritic density of the UG animals at PD 12 on circles 3, and 4, at PD 20 on circle 4, as well as on circles 1,2 , and 4 at PD 30. The cumulative effects of undernutrition on the density of branches showed significantly reduced values $(\mathrm{p}<0.05)$ in the UG dendritic density measurement at PDs 12 and 30 (Figure 2(b)).

\subsection{Perikarya Effects}

Comparisons of the perikarya scores yielded significant reductions of the neuron cross sectional area in the UG subjects, $\mathrm{F}(1,102)=87.12$, $\mathrm{p}<0.0001$, and also by age, $\mathrm{F}(2,102)=14.84, \mathrm{p}<0.0002$, without significant interaction between factors. Post hoc comparisons indicated significant $(p<0.05)$ score reductions of cross sectional area with increasing age in the UG animals ((Figure 3(a)). The cumulative effects of underfeding over all ages indicated a significant reduction ( $p<0.05)$ of cross sectional area in the UG animals (Figure 3(a)).

The perimeter comparisons of perikarya indicated significant reductions in the UG animals associated with diet, $F(1,102)=51.05$, $p<0.0001$, and age, $F(2,102)=$ 19.03, $\mathrm{p}<0.0001$, with no interaction between factors. Post hoc comparisons along the days of the study yielded significantly $(p<0.05)$ reduced values as developmental age increased (Figure 3(b)). The cumulative effects of 

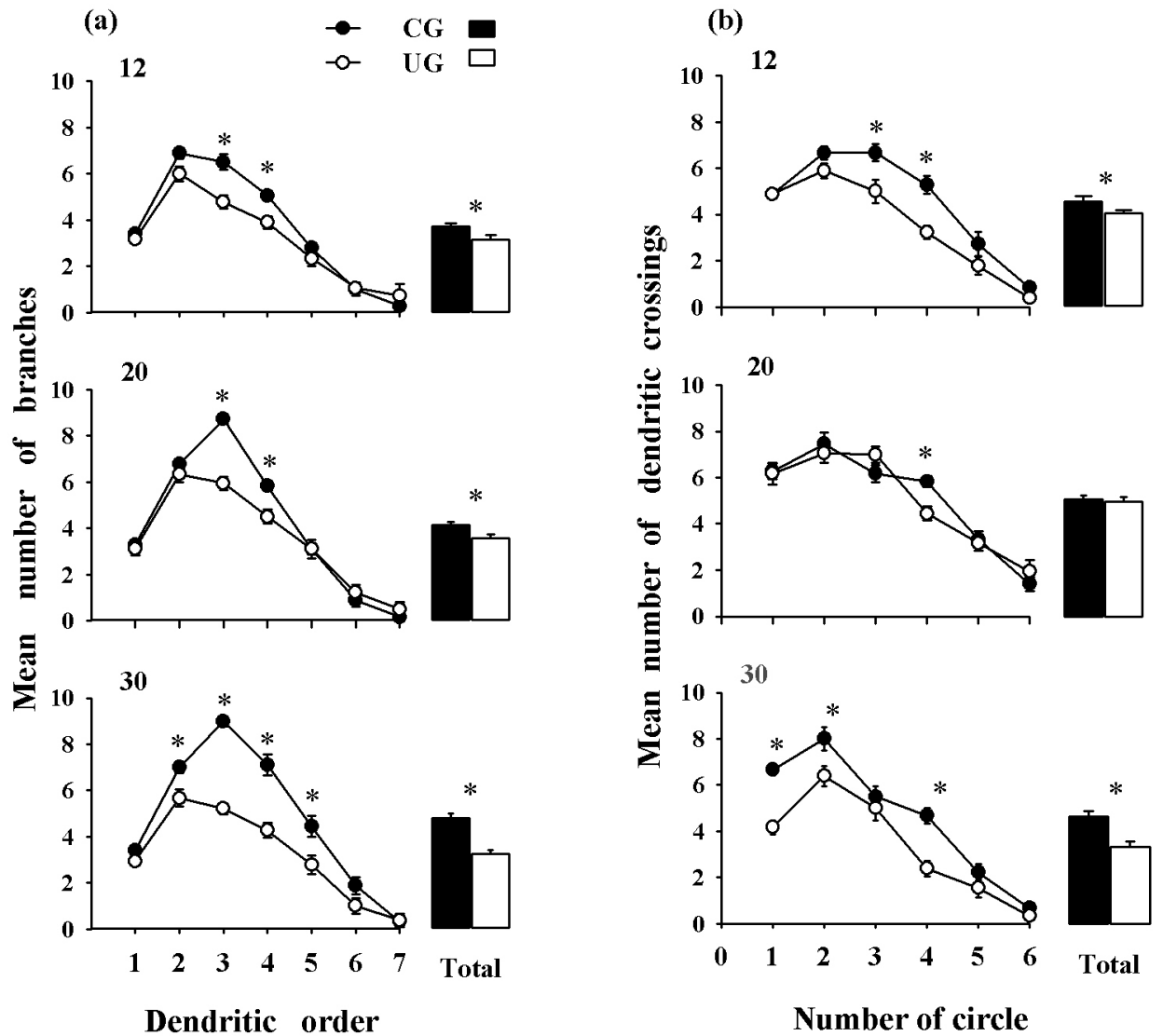

Figure 2. Mean values \pm SEM of (a) dendritic orders and (b) dendritic density of pyramidal neurons (n = 18/age group) from different experimental groups and ages. Note, the reduced dendritic values at the distal portions of the arbor, in the UG animals. The cumulative effects of undernutrition (see text) showed significant reductions in the UG rats. ${ }^{*} p<0.05$ ). The average of all ages is shown as Total.

undernutrition on the neuronal perimeter showed significantly reduced values $(\mathrm{p}<0.05)$ with age in the UG subjects (Figure 3(b)).

\subsection{Dendritic Spine Effects}

Comparisons of the number of dendritic spines showed significant reductions in the UG subjects, $\mathrm{F}(1,96)=1172$. 39, $\mathrm{p}<0.0001$, and changes with age, $\mathrm{F}(2,96)=1596.32$, $\mathrm{p}<0.0001$, and a significant interaction diet by age, $\mathrm{F}(2$, $96)=37.05, \mathrm{p}<0.0001$. Post hoc comparisons indicated significant reductions $(\mathrm{p}<0.05)$ in the UG values on all days tested (Figure 3(c)). The cumulative comparison of the number of spines averaged over all ages showed significantly $(\mathrm{p}<0.05)$ reduced values in the pyramidal neurons obtained from UG subjects (Figure 3(c)).

\section{Discussion}

The significant reductions in the body and brain weights of the UG subjects throughout the study are in line with previous work showing that different underfeeding paradigms in rats interfere with the physical growth, delay sensory development, delay social behavior, and cause hyper-responsiveness to novel exposure, low vocalizations, and poor maternal care which is necessary for pup s' survival and brain growth [1,5,22,24,41]. Additionally, our data on the effects of neonatal undernutrition and the delayed physical development of pups may also be associated with maternal deprivation because of the daily transfer of the pups to the incubator and 12-h separation from the mother, in spite of the increased of maternal manipulation and licking of pups upon their return and later in the home-cage environment [33-35]. By contrast, when the individual pup's daily separation is only 1-h, body and brain weights were not significantly different between the experimental groups [27]. The findings obtained here with a daily 12-h separation from the mother may also reflect a decrease of environmental sensory stimulation; this decrease impairs the release of epidermal growth factor (EGF), growth hormone (GH), and the ornithine decarboxylase (ODC) enzyme all of which influence protein synthesis in the CNS and may also interfere with the pup's physical development [42-45].

Current findings showed that the underfeeding para- 


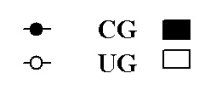

(a)

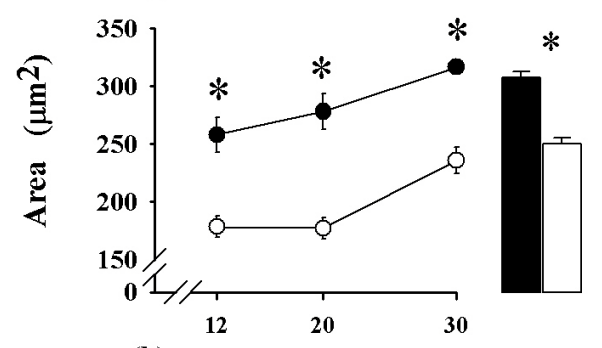

(b)

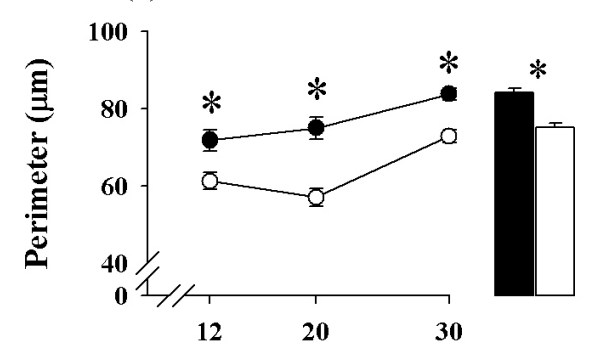

(c)

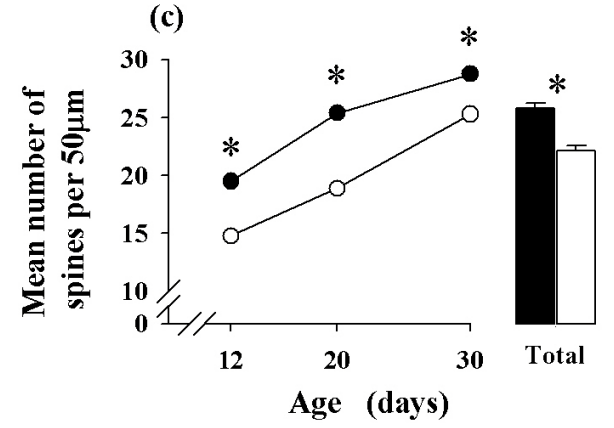

Figure 3. Mean values \pm SEM of (a) area, (b) perimeter of perikarya ( $n=18$ /age group), and (c) number of basilar spines of pyramidal neurons $(n=17 /$ age group) of different experimental groups and ages. Note, the reduced perikarya and dendritic spine measurements throughout the study and their gradual increase with age. The cumulative effects of undernutrition (see text) showed significant reductions in the UG subjects. ${ }^{*} \mathrm{p}<0.05$.

digm reduced the number and arborization of basilar dendrites, and spine density, with a significant decrease in the perimeter and cross sectional area of the perikarya of dlPFC layer III pyramidal neurons. These alterations may interfere with the neuronal integrative processes occurring in this structure in response to cortical polysensory associative inputs, and the thalamocortical ascending system upon the reduced pyramidal dendritic spine density. This interference may disrupt different levels of pyramidal neurons threshold activation related to the effects of spatiotemporal patterns of stimulation resulting in altered dlPFC cognitive processes [9,12,46,47]. Another point of interest is that neonatal underfeeding paradigm is a powerful stressor that may interfere with the connectivity of dIPFC neurons and their functional interactions, accompanied by the increased glucocorticoid release that reprograms the HPA axis of the newborn to give nonadaptive behavioral responses $[14,48,49]$. In this regard, the alterations in the neuronal discharges of the dIPFC directed to the limbic system may bring about deficiencies in the central states of adaptive, cognitive, executive, attentional, hyperactive, fear, and anxiety responses during the neonatal period highly dependent on the maternal influence, and these deficiencies may manifest at later ages as exploratory, learning and affective disorders related to the sensory environmental input $[9,21$, 47,50-52]. The present results support the idea that both pre- and neonatal food deprivations in rats result at the adult stage, in reduced exploratory behavior, with episodes of hyperactivity or freezing activity, and increased selfgrooming, fecal boli, and urine elimination during exposure to an open field or an elevated plusmaze test [53-55].

Additionally, the atrophy of the distal portions of the basilar dendrites and the reduced spine density of the dIPFC neurons may be important cellular features of both neonatal undernourishment and stress-related disorders, where the increased glucocorticoid levels may interfere with ornithine decarboxylase (ODC) activity, the reduction in the BDNF content or perhaps some other synaptic organizers such as Wnt5a secreted proteins that inhibit local protein synthesis causing deficits in neuronal microtubules, and in the assembly of excitatory dendritic spines [56-58].

\section{Conclusion}

Finally, our findings indicate that not only the prenatal but also the neonatal period is a critical time window for the developing rat, where layer III dIPFC neurons are highly vulnerable to a number of epigenetic factors such as food restriction, sensory deprivation, maternal stress, and interference with mother-litter-bonds. However, further information using the current underfeeding paradigm is required to identify the mechanisms underlying the effects of prolonged separation of mother and pups on the pups' dendritic arbor and spines, its effects on the mother's cognitive brain structures, and the correlation between these effects and the long-term cognitive disorders that occur in perinatally underfed rodents.

\section{Acknowledgements}

The work was partly supported by DGAPA/UNAM, IN200413. We thank Dr. Dorothy Pless for editorial assistance and suggestions; K. Guzman for collecting data; N. Hernandez and L. Lopez for neuronal image reconstruction.

\section{REFERENCES}

[1] D. A. Callison and J. W. Spencer, "Effect of Chronic 
Undernutrition and/or Visual Deprivation Upon the Visual Evoked Potential from the Developing Rat Brain,” Developmental Psychobiology, Vol. 1, No. 3, 1968, pp. 196204. http://dx.doi.org/10.1002/dev.420010308

[2] N. M. Bass, M. G. Netsky and E. Young, "Effect of Neonatal Malnutrition on Developing Cerebrum. 1. Microchemical and Histologic Study of Cellular Differentiation in the Rat," Archives of Neurology (Chic), Vol. 23, No. 4, 1970, pp. 289-302.

[3] B. M. Lester, R. E. Klein and S. J. Martinez, "The Use of Habituation in the Study of the Effects of Infantile Malnutrition,” Developmental Psychobiology, Vol. 8, No. 6, 1975, pp. 541-546.

http://dx.doi.org/10.1002/dev.420080611

[4] J. L. Smart, "Maternal Behaviour of Undernourished Mother Rats toward Well Fed and Underfed Young," Physiology and Behavior, Vol. 16, No. 2, 1976, pp. 147-149. http://dx.doi.org/10.1016/0031-9384(76)90298-5

[5] A. Hernandez, S. Ruiz, H. Perez and R. Soto-Moyano, "Effect of Early Malnutrition on Dynamic Properties of Axodendritic Synapses in the Rat Prefrontal Cortex," Journal of Neurobiology, Vol. 16, No. 5, 1985, pp. 389393 http://dx.doi.org/10.1002/neu.480160505

[6] L. F. Campbell and K. S. Bedi, "The Effects of Undernutrition during Early Life on Spatial Learning,” Physiology and Behavior, Vol. 45, No. 5, 1989, pp. 883-890. http://dx.doi.org/10.1016/0031-9384(89)90210-2

[7] C. Escobar and M. Salas, "Neonatal Undernutrition and Amygdaloid Nuclear Complex Development: An Experimental Study in the Rat,” Experimental Neurology, Vol. 122, No. 2, 1993, pp. 311-318. http://dx.doi.org/10.1006/exnr.1993.1130

[8] E. Susser, R. Neugebauer, H. W. Hoek, A. S. Brown, S. Lin, D. Labovitz and J. M. Gorman, "Schizophrenia after Prenatal Femine. Further Evidence,” Archives General Psychiatry, Vol. 53, No. 1, 1996, pp. 25-31. http://dx.doi.org/10.1001/archpsyc.1996.0183001002700 $\underline{5}$

[9] W. E. Bunney and B. G. Bunney, "Evidence for a Compromised Dorsolateral Prefrontal Cortical Parallel Circuit in Schizophrenia," Brain Research Reviews, Vol. 31, No. 2-3, 2000, pp. 138-146. http://dx.doi.org/10.1016/S0165-0173(99)00031-4

[10] Y. Goto and A. A. Grace, "Dopaminergic Modulation of Limbic and Cortical Drive of Nucleus Accumbens in Goal-Directed Behavior,” Nature Neuroscience, Vol. 8, No. 6, 2005, pp. 805-812. http://dx.doi.org/10.1038/nn1471

[11] M. Salas, "Effects of Early Undernutrition on Dendritic Spines of Cortical Pyramidal Cells in the Rat," Developmental Neuroscience, Vol. 3, No. 3, 1980, pp. 109-117. http://dx.doi.org/10.1159/000112384

[12] J. W. Brock and C. Prasad, "Alterations in Dendritic Spine Density in the Rat Brain Associated with Protein Malnutrition,” Developmental Brain Research, Vol. 66, No. 2, 1992, pp. 266-269. http://dx.doi.org/10.1016/0165-3806(92)90090-J

[13] L. J. Garey, W. Y. Ong, T. S. Patel, M. Kanani, A. Davis, A. M. Mortimer, T. R. E. Barnes and S. R. Hirsch, "Re- duced Dendritic Spine Density on Cerebral Cortical Pyramidal Neurons in Schizophrenia," Journal of Neurology Neurosurgery Psychiatry, Vol. 65, No. 4, 1998, pp. 446453. http://dx.doi.org/10.1136/jnnp.65.4.446

[14] L. A. Glantz and D. A. Lewis, "Decreased Dendritic Spine Density on Prefrontal Cortical Pyramidal Neurons in Schizophrenia," Archives Genetics Psychiatry, Vol. 57, No. 1, 2000, pp. 65-73. http://dx.doi.org/10.1001/archpsyc.57.1.65

[15] M. S. Murmu, S. Salomon, Y. Biala, M. Weinstock, K Braun and J. Bock, "Changes of Spine Density and Dendritic Complexity in the Prefrontal Cortex in Offspring of Mothers Exposed to Stress during Pregnancy,” European Journal of Neuroscience, Vol. 24, No. 5, 2006, pp. 14771487. http://dx.doi.org/10.1111/j.1460-9568.2006.05024.x

[16] M. Salas, S. Diaz and A. Nieto, "Effects of Neonatal Food Deprivation on Cortical Spines and Dendritic Development of the Rat,” Brain Research, Vol. 73, No. 1, 1974, pp. 139-144. http://dx.doi.org/10.1016/0006-8993(74)91012-9

[17] B. A. Brody and K. H. Pribram, "The Role of Frontal and Parietal Cortex in Cognitive Processing: Tests of Spatial and Sequence Functions,” Brain, Vol. 101, No. 4, 1978, pp. 607-633. http://dx.doi.org/10.1093/brain/101.4.607

[18] H. Perez, S. Ruiz, A. Hernandez and R. Soto-Moyano, "Effect of Early Undernutrition on Reactivity of the Rat Parietal Association Area,” Experimental Neurology, Vol. 82, No. 1, 1983, pp. 241-244.

[19] M. R. Rosenzweigh and E. L. Bennett, "Psychobiology of Plasticity: Effects of Training and Experience on Brain and Behavior,” Behavioral Brain Research, Vol. 78, No. 1, 1996, pp. 57-65. http://dx.doi.org/10.1016/0166-4328(95)00216-2

[20] A. S. Fleming, D. H. O’Day and G. W. Kraemer, “Neurobiology of Mother-Infant Interactions: Experience and Central Nervous System Plasticity across Development and Generations," Neuroscience Biobehavioral Reviews, Vol. 23, No. 5, 1999, pp. 673-685. http://dx.doi.org/10.1016/S0149-7634(99)00011-1

[21] S. Macri and H. Würbel, "Developmental Plasticity of HPA and Fear Responses in Rats: A Critical Review of the Maternal Mediation Hypothesis," Hormones and Behavior, Vol. 50, No. 5, 2006, pp. 667-680. http://dx.doi.org/10.1016/j.yhbeh.2006.06.015

[22] M. Salas, C. Torrero and S. Pulido, "Long-Term Alterations in the Maternal Behavior of Neonatally Undernourished Rats,” Physiology and Behavior, Vol. 33, No. 2, 1984, pp. 273-278. http://dx.doi.org/10.1016/0031-9384(84)90111-2

[23] M. Meaney, J. Dioro, D. Francis, J. Woddowson, P. La Plante, C. Caldji, S. Sharma, J. R. Seckl and P. M. Plotsky, "Early Environmental Regulation of Forebrain Glucocorticoid Receptor Gene Expression: Implications for Adrenocortical Responses to Stress,” Developmental Neuroscience, Vol. 18, No. 1-2, 1996, pp. 49-72. http://dx.doi.org/10.1159/000111395

[24] M. Salas, C. Torrero, M. Regalado and E. Perez, "Retrieving of Pups by Neonatally Stressed Mothers,” Nutri- 
tional Neuroscience, Vol. 5, No. 6, 2002, pp. 399-405. http://dx.doi.org/10.1080/1028415021000055943

[25] M. Leonhardt, S. G. Mathhews, M. J. Meaney and C. D. Walker, "Psychological Stressors as a Model of Maternal Adversity: Diurnal Modulation of Corticosterone Responses and Changes in Maternal Behavior," Hormones and Behavior, Vol. 51, No. 1, 2007, pp. 77-88. http://dx.doi.org/10.1016/j.yhbeh.2006.08.008

[26] J. Leah, H. Allardyce and H. Cummins, "Evoked Cortical Potentials Correlates of Rearing Environments in Rats," Biology Psychology, Vol. 20, No. 1, 1985, pp. 21-29. http://dx.doi.org/10.1016/0301-0511(85)90038-9

[27] J. Bock, M. Gruss, S. Becker and K. Braun, "ExperienceInduced Changes of Dendritic Spine Densities in Prefrontal and Sensory Cortex: Correlation with Developmental Time Windows," Cerebral Cortex, Vol. 15, No. 6, 2005 pp. 802-808. http://dx.doi.org/10.1093/cercor/bhh181

[28] R. Pascual and S. P. Zamora-Leon, "Effects of Neonatal Maternal Deprivation and Postweaning Environmental Complexity on Dendritic Morphology of Prefrontal Pyramidal Neurons in the Rat," Acta Neurobiologiae Experimentalis (Wars), Vol. 67, No. 4, 2007. pp. 471-479. http://dx.doi.org/10.1002/dneu.20622

[29] E. Monroy, E. Hernandez-Torres and G. Flores, "Maternal Separation Disrupts Dendritic Morphology of Neurons in Prefrontal Cortex, Hippocampus, and Nucleus Accumbens in Male Rat Offspring," Journal of Chemical Neuroanatomy, Vol. 40, No.2, 2010, pp. 93-110. http://dx.doi.org/10.1016/j.jchemneu.2010.05.005

[30] S. Crnic, J. M. Bell, R. Mangold, M. Gruenthal, M. J. Eiler and S. Finger, "Separation-Induced Early Malnutrition: Maternal, Physiological and Behavioral Effects," Physiology and Behavior, Vol. 26, No. 4, 1981, pp. 695707. http://dx.doi.org/10.1016/0031-9384(81)90147-5

[31] National Research Council, "Guidelines for the Care and use of mammals," In: National Research Council of the National Academies Neuroscience and Behavioral Research. National Academies Press, Washington DC, 2003, p. 209.

[32] J. G. Vanderbergh, "Prenatal Hormone Exposure and Sexual Variation,” American Scientist, Vol. 91, No. 3, 2003, pp. 218-225. http://dx.doi.org/10.1511/2003.3.218

[33] M. H. S. Lee and D. I. Williams, "Changes in Licking Behaviour of Rat Mother Following Handling of Young," Animal Behaviour, Vol. 22, No. 3, 1974, pp. 679-681. http://dx.doi.org/10.1016/S0003-3472(74)80016-3

[34] C. R. Pryce, D. Bettschen and D. Feldon, "Comparison of the Effects of Early Handling and Early Deprivation on Maternal Care in the Rat,” Developmental Psychobiology, Vol. 38, No. 4, 2001, pp. 239-251. http://dx.doi.org/10.1002/dev.1018

[35] S. Macri, G. J. Mason and H. Würbel, "Dissociation in the Effects of Neonatal Maternal Separations on Maternal Care and the Offspring's HPA and Fear Responses in Rats,” European Journal of Neurosciences, Vol. 20, No. 4, 2004, pp. 1017-1024. http://dx.doi.org/10.1111/j.1460-9568.2004.03541.x

[36] J. Altman and S. A. Bayer, “Atlas of Prenatal Rat Brain
Development,” CRC Press, Boca Raton, 1995.

[37] A. Lynch, "Postnatal Undernutrition: An Alternative Method," Developmental Psychobiology, Vol. 9, No. 1, 1976, pp. 39-48. http://dx.doi.org/10.1002/dev.420090107

[38] M. E. Scheibel and A. B. Scheibel, "Structural Substrates for Integrative Patterns in the Brain Stem Reticular Core," In: H. H. Jasper, et al., Eds., Reticular Formation of the Brain, Little Brown, Boston, 1958, pp. 31-55. http://dx.doi.org/10.1037/h0039515

[39] G. Paxinos and C. Watson, "The Rat Brain in Stereotaxic Coordinates,” Academic Press Inc., San Diego, 1986.

[40] D. A. Sholl, "The Organization of the Cerebral Cortex," Halfner, New York, 1956.

[41] J. Tonkiss, K. Hosokawa, K. Yabusaki and T. Obinata, "Ultrasonic Call Characteristics of Rat Pups Are Altered following Prenatal Malnutrition,” Developmental Psychobiology, Vol. 43, No. 2, 2003, pp. 90-101. http://dx.doi.org/10.1002/dev.10124

[42] C. M. Khum, S. R. Butler and S. M. Schanbergh, "Selective Depression of Serum Growth Hormone during Maternal Deprivation in Rat Pups,” Science, Vol. 201, No. 4360, 1978, pp. 1034-1036. http://dx.doi.org/10.1126/science.684424

[43] G. E. Evoniuk, C. M. Kuhn and S. M. Schanbergh, "The Effect of Tactile Stimulation on Serum Growth Hormone and Tissue Ornithine Decarboxylase Activity during Maternal Deprivation in Rat Pups," Communications in Psychopharmacology, Vol. 3, No. 5, 1979, pp. 363-370.

[44] S. M. Schanbergh, G. E. Evoniuk and C. M. Kuhn, “Tactile and Nutritional Aspects of Maternal Care: Specific Regulators of Neuroendocrine Function and Cellular Development," Proceedings of the Society for Experimental Biology and Medicine, Vol. 175, No. 2, 1984, pp.135-146. http://dx.doi.org/10.3181/00379727-175-417 $\underline{79}$

[45] J. M. Ketelslegers, D. Maiter, M. Maes, L. E. Underwood and J. P. Thissen, "Nutritional Regulation of the Growth Hormone and Insulin-Like Growth-Binding Proteins," Hormone Research, Vol. 45, No. 3-5, 1996, pp. 252-257. http://dx.doi.org/10.1159/000184797

[46] J. E. Krettek and J. L. Price, "The Cortical Projections of the Mediodorsal Nucleus and Adjacent Thalamic Nuclei in the Rat," Journal of Comparative Neurology, Vol. 171, No. 2, 1977, pp. 157-191. http://dx.doi.org/10.1002/cne.901710204

[47] R. M. Sullivan and W. G. Brake, "What the Rodent Prefrontal Cortex can Teach us about Attention-Deficit/Hyperactivity Disorder: The Critical Role of Early Developmental Events on Prefrontal Function,” Behavioral Brain Research, Vol. 146, No. 1-2, 2003, pp. 43-55. http://dx.doi.org/10.1016/j.bbr.2003.09.015

[48] L. Lacroix, S. Spinelli, A. Christian and J. Feldon, "Differential Role of the Medial and Lateral Prefrontal Cortices in Fear and Anxiety,” Behavioral Neuroscience, Vol. 114, No. 6, 2000, pp. 1119-1130. http://dx.doi.org/10.1037/0735-7044.114.6.1119

[49] E. G. Curtis, K. Sung-Jae and J. M. Rogers, "Maternal Influences and Epigenetic Programming of the Develop- 
ing Hypothalamic-Pituitary-Adrenal Axis,” Birth Defects Research Part A, Vol. 91, No. 8, 2011, pp. 797-805. http://dx.doi.org/10.1002/bdra.20824

[50] C. Caldji, B. Tannebaum, S. Sharma, D. Francis, P. M. Plotsky and M. J. Meaney, "Maternal Care during Infancy Regulates the Development of Neural Systems Mediating the Expression of Fearfulness in the Rat," Proceedings of the National Academy of Sciences of the United States of America, Vol. 95, No. 9, 1998, pp. 5335-5340. http://dx.doi.org/10.1073/pnas.95.9.5335

[51] S. Moriceau and R. M. Sullivan, "Maternal Presence Serves as a Switch between Learning Fear and Attraction in Infancy,” Nature Neuroscience, Vol. 9, No 8, 2006, pp. 1004-1006. http://dx.doi.org/10.1038/nn1733

[52] J. E. Markham and J. I. Koening, "Prenatal Stress: Role in Psychiatric and Depressive Diseases," Psychopharmacology, Vol. 214, No. 1, 2011, pp. 89-106.

[53] M. Salas and L. Cintra, "Influence of Early Food Restriction on the Responsiveness to Novel Stimuli in Adult Rats,” Boletín de Estudios Médicos y Biológicos, México, Vol. 30, No. 1, 1979, pp. 201-204.

[54] S. S. Almeida, R. A. Garcia and L. M. de Olveira, "Effects of Early Protein Malnutrition and Repeated Testing upon Locomotor and Exploratory Behaviors in the Elevated Plus-Maze,” Physiology and Behavior, Vol. 54, No. 4, 1993, pp. 749-752. http://dx.doi.org/10.1016/0031-9384(93)90086-U
[55] R. Bousalham, B. Benazzoouz, A. El Hessni, A. Ouichou and A. Mesfioui, "Maternal Separation Affects Mothers' Affective and Reproductive Behaviors as Well as Second Offspring's Emotionality,” Journal of Behavioural and Brain Science, Vol. 3, No. 5, 2013, pp. 409-414. http://dx.doi.org/10.4236/jbbs.2013.35042

[56] S. M. Schanberg, V. F. Ingledue, J. Y. Lee, Y. A. Hannun and J. V. Bartolome, "PKC Alpha Mediates Maternal Touch Regulation of Growth-Related Gene Expression in Infant Rats,” Neuropsychopharmacology, Vo. 28, No. 6, 2003, pp. 1026-1030.

[57] B. Coupé, I. Dutriez-Casteloot, C. Breton, F. Lefévre, J. Mairesse, A. Dickes-Coopman, M. Silhol, L. Tapia-Arancibia, J. Lesage and D. Vieau, "Perinatal Undernutrition Modifies Cell Proliferation and Brain-Derived Neurotrophic Factor Levels during Critical Time-Windows for Hypothalamic and Hippocampal Development in the Male Rat,” Journal of Neuroendocrinology, Vol. 21. No. 1, 2009, pp. 40-48. http://dx.doi.org/10.1111/j.1365-2826.2008.01806.x

[58] L. Ciani, K. A, Boyle, E. Dickins, M. Sahores, D. Anane, D. M. Lopes, A. J. Gibb and P. C. Salinas, "Wnt7 Signaling Promotes Dendritic Spine Growth and Synaptic Strengh through $\mathrm{Ca}^{2+} /$ Calmodulin-Dependent Protein Kinase II," Proceedings of the National Academy of Sciences of the United States of America, Vol. 108, No. 26, 2011, pp. 10732-10737. http://dx.doi.org/10.1073/pnas.1018132108 